\title{
Synaptic Plasticity at Inhibitory Synapses in the Ventral Tegmental Area Depends upon Stimulation Site
}

\author{
Robyn St. Laurent and Julie Kauer
}

https://doi.org/10.1523/ENEURO.0137-19.2019

Department of Psychiatry and Behavioral Sciences, Stanford University School of Medicine, Stanford, CA 94305

\begin{abstract}
Drug exposure induces cell and synaptic plasticity within the brain reward pathway that could be a catalyst for progression to addiction. Several cellular adaptations have been described in the ventral tegmental area (VTA), a central component of the reward pathway that is the major source of dopamine release. For example, administration of morphine induces long-term potentiation (LTP) of excitatory synapses on VTA dopamine cells and blocks LTP at inhibitory synapses. Drug-induced synaptic changes have a common endpoint of increasing dopamine cell firing and dopamine release. However, gaining a complete picture of synaptic plasticity in the VTA is hindered by its complex circuitry of efferents and afferents. Most studies of synaptic plasticity in the VTA activated a mixed population of afferents, potentially yielding an incomplete and perhaps misleading view of how drugs of abuse modify VTA synapses. Here, we use midbrain slices from mice and find that electrical stimulation in two different regions induces different forms of plasticity, including two new forms of LTP at inhibitory synapses. High-frequency stimulation (HFS) induces LTP independently of NMDA receptor (NMDAR) activation, and surprisingly, some inhibitory inputs to the VTA also undergo NMDAR-independent LTP after a low-frequency stimulation (LFS) pairing protocol.
\end{abstract}

Key words: dopamine; electrophysiology; GABA; midbrain; potentiation; synaptic plasticity

\section{Significance Statement}

Synaptic plasticity of inhibitory inputs onto dopamine cells in the ventral tegmental area (VTA) has a major influence on the circuits implicated in addictive behaviors. The location of electrical stimulation in an acute midbrain slice dictated the response of inhibitory inputs to plasticity induction protocols. We describe a new form of synaptic strengthening that occurs at an opioid-sensitive input to the VTA.

\section{Introduction}

The ventral tegmental area (VTA) contains dopaminergic cells that receive inhibitory innervation from GABAer-

\footnotetext{
Received April 10, 2019; accepted October 4, 2019; First published October 16,2019

The authors declare no competing financial interests.

Author contributions: R.S.L. and J.K. designed research; R.S.L. performed research; R.S.L. analyzed data; R.S.L. and J.K. wrote the paper.

This work was supported by Department of Health and Human Services National Institutes of Health National Institute on Drug Abuse Grants 011289 (to J.K.), 045419 (to R.S.L.), and T32 MH20068 (to R.S.L.).

R. St. Laurent's present address: Gladstone Institutes, San Francisco, CA 94158.

Acknowledgements: We thank Ayumi Tsuda for technical help.
}

gic cell bodies originating within the VTA and from many other brain regions (Watabe-Uchida et al., 2012; Beier et al., 2015). Despite a wealth of anatomical and behavioral studies investigating the diversity of VTA afferents, plasticity at inhibitory synapses was historically described without identification of the presynaptic partner (Melis

Correspondence should be addressed to Julie Kauer at jkauer@stanford.edu. https://doi.org/10.1523/ENEURO.0137-19.2019

Copyright (C) 2019 St. Laurent and Kauer

This is an open-access article distributed under the terms of the Creative Commons Attribution 4.0 International license, which permits unrestricted use, distribution and reproduction in any medium provided that the original work is properly attributed. 
et al., 2002; Liu et al., 2005; Nugent et al., 2007, 2009; Niehaus et al., 2010; Dacher and Nugent, 2011; Padgett et al., 2012; Graziane et al., 2013; Kodangattil et al., 2013; Polter et al., 2014). For example, nitric-oxide-dependent long-term potentiation (LTP ${ }_{\text {GABA }}$ ) can be triggered using electrical stimulation within the VTA (Nugent et al., 2007); however, when specific afferents were isolated using optogenetics, induction of LTP the presynaptic partner (Simmons et al., 2017; Polter et al., 2018). Specifically, $L T P_{G A B A}$ is expressed at nucleus accumbens and VTA GABA $A_{A}$ synapses, but not rostromedial tegmental nucleus (RMTg)-originating $\mathrm{GABA}_{\mathrm{A}}$ synapses. These observations demonstrate that all GABAergic synapses cannot be assumed to share a common plasticity mechanism. The idea that plasticity is segregated to specific populations is not a new one, and in fact many reports segregate experiments by postsynaptic cell identity. For example, long-term depression (LTD) induced by low-frequency afferent stimulation is only expressed in putative dopamine cells in the VTA that express large $\mathrm{H}$ currents ( $l_{h}$; Dacher and Nugent, 2011). With local electrical stimulation in acute slices, it is possible to isolate synapses of one neurotransmitter type pharmacologically, but the identity of the presynaptic source is not always as easy to manipulate or determine. Although the location of the postsynaptic VTA cell (e.g., medial vs lateral VTA) can sometimes predict output site, inputs from over 20 brain regions contact dopamine cells in all VTA subregions (Beier et al., 2015). It is possible that other plasticity mechanisms have yet to be uncovered because their expression is limited to a subset of inputs, and therefore not apparent with global activation of all inputs. Here, we use different electrical stimulation sites, and report two ways of inducing LTP at inhibitory synapses in the VTA with a mechanism(s) that is non-overlapping with that of LTP $_{\text {GABA }}$ or other known forms of LTP at inhibitory synapses in the VTA.

\section{Materials and Methods}

\section{Animals}

All procedures were conducted in accordance with the guidelines of the National Institutes of Health for animal care and use and were approved by the Brown University and Stanford University Institutional Animal Care and Use Committees. This study used VGAT::IRES-Cre (RRID: IMSR_JAX:028862, strain code: B6J.129S6(FVB)-

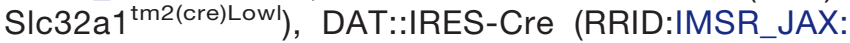

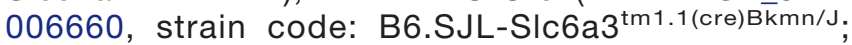
Zhuang et al., 2005), Ai14 Cre-reporter mice (RRID: IMSR_JAX:007908, strain code: B6;129S6-

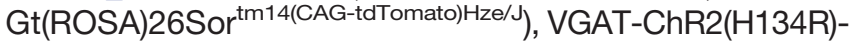
EYFP (RRID:IMSR_JAX:014548, strain code: B6.Cg$\mathrm{Tg}$ (Slc32a1-COP4*H134R/EYFP)8Gfng/J; (Zhao et al., 2011), and C57BL/6 (RRID:IMSR_JAX:000664) male and female mice bred in-house. Mice were maintained on a 12/12 $\mathrm{h}$ light/dark cycle and provided food and water ad libitum.

\section{Preparation of brain slices}

Horizontal brain slices $(220 \mu \mathrm{m})$ were prepared from deeply anesthetized mice. Briefly, anesthetized mice were
A

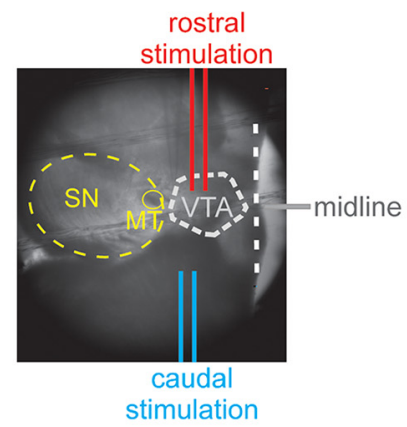

C

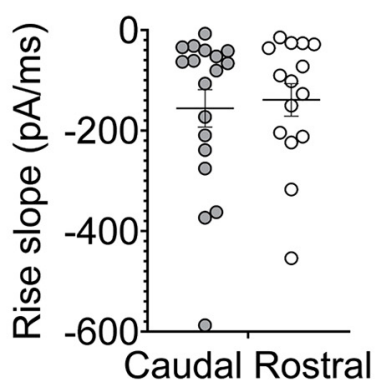

E baseline $1 \mu \mathrm{M}$ DAMGO

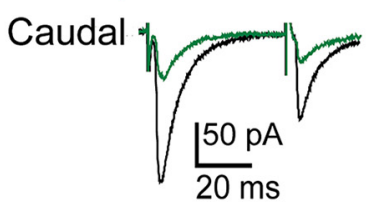

Rostral
B

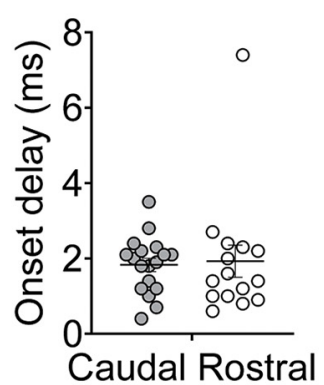

D

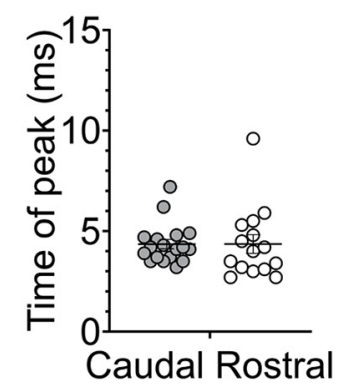

Figure 1. Electrical stimulation in horizontal midbrain slices. $\boldsymbol{A}$, Recording setup illustrating caudal or rostral placements of the bipolar stimulating electrodes. Analysis of caudal versus rostral IPSC: onset delay $(\boldsymbol{B})$, rise slope $(\boldsymbol{C})$, and time to peak amplitude $(\boldsymbol{D})$. $\boldsymbol{E}$, Example IPSCs illustrating control IPSCs (black) and in the $\mu$-opioid receptor agonist, DAMGO $(1 \mu \mathrm{M}$; green), for caudal or rostral inputs. $\boldsymbol{F}$, Mean IPSC amplitude depression after DAMGO (1 $\mu \mathrm{M})$, for each input. Error bars represent SEM.

perfused with ice-cold oxygenated artificial CSF (ACSF): $126 \mathrm{mM} \mathrm{NaCl}, 21.4 \mathrm{mM} \mathrm{NaHCO}_{3}, 2.5 \mathrm{mM} \mathrm{KCl}, 1.2 \mathrm{mM}$ $\mathrm{NaH}_{2} \mathrm{PO}_{4}, 2.4 \mathrm{mM} \mathrm{CaCl}, 1.0 \mathrm{mM} \mathrm{MgSO}$, $11.1 \mathrm{mM}$ glucose, and $5 \mathrm{mM}$ sodium ascorbate. Following perfusion, the brain was rapidly dissected and horizontal slices (220 $\mu \mathrm{m})$ were prepared using a vibratome. Slices recovered for $1 \mathrm{~h}$ at $34^{\circ} \mathrm{C}$ in oxygenated HEPES holding solution: 86 $\mathrm{mM} \mathrm{NaCl}, 2.5 \mathrm{mM} \mathrm{KCl}, 1.2 \mathrm{mM} \mathrm{NaH} \mathrm{PO}_{4}, 35 \mathrm{mM}$ $\mathrm{NaHCO}_{3}, 20 \mathrm{mM}$ HEPES, $25 \mathrm{mM}$ glucose, $5 \mathrm{mM}$ sodium ascorbate, $2 \mathrm{mM}$ thiourea, $3 \mathrm{mM}$ sodium pyruvate, $1 \mathrm{mM}$ $\mathrm{MgSO}_{4}$, and $2 \mathrm{mM} \mathrm{CaCl}_{2}$ (Ting et al., 2014), and then were 
Table 1. Statistical table

\begin{tabular}{|c|c|c|}
\hline Data structure & Type of test & 95\% confidence interval \\
\hline${ }^{a}$ Normal distribution & Two-tailed unpaired $t$ test & -0.79 to 0.98 \\
\hline bNormal distribution & Two-tailed unpaired $t$ test & -85.83 to 119.6 \\
\hline${ }^{\mathrm{C}}$ Normal distribution & Two-tailed unpaired $t$ test & -0.99 to 1.01 \\
\hline${ }^{\mathrm{d}}$ Normal distribution & Two-tailed unpaired $t$ test & -27.21 to 32.06 \\
\hline eNormal distribution & Two-tailed paired $t$ test & 18.20 to 162.8 \\
\hline${ }^{f}$ Normal distribution & Two-tailed paired $t$ test & -78.82 to 59.01 \\
\hline 9Normal distribution & Two-tailed paired $t$ test & -0.43 to -0.002 \\
\hline${ }^{\mathrm{h}}$ Normal distribution & Two-tailed paired $t$ test & -2.47 to 3.56 \\
\hline 'Normal distribution & Two-tailed paired $t$ test & 5.89 to 85.91 \\
\hline${ }^{\mathrm{j} N o r m a l}$ distribution & Two-tailed paired $t$ test & -0.17 to 0.0029 \\
\hline kNormal distribution & Two-tailed paired $t$ test & -0.38 to 4.43 \\
\hline 'Normal distribution & Two-tailed paired $t$ test & -87.36 to 104.7 \\
\hline${ }^{\mathrm{m}}$ Normal distribution & Two-tailed paired $t$ test & -0.15 to 0.15 \\
\hline nNormal distribution & Two-tailed paired $t$ test & -9.54 to 10.06 \\
\hline 'Normal distribution & Two-tailed paired $t$ test & 37.01 to 147.8 \\
\hline PNormal distribution & Two-tailed paired $t$ test & -0.21 to 0.13 \\
\hline वNormal distribution & Two-tailed paired $t$ test & 1.22 to 110.4 \\
\hline 'Normal distribution & One-way ANOVA & High EGTA 99.09-210.7; GDP- $\beta$-S 115.9-153.4 \\
\hline
\end{tabular}

held in the same HEPES solution at room temperature until use. Slices were then transferred to a recording chamber where they were submerged in ACSF without sodium ascorbate.

\section{Electrophysiology}

Electrophysiological experiments were performed in horizontal midbrain slices containing the VTA that were continuously perfused with ACSF containing $10 \mu \mathrm{M}$ 6,7dinitroquinoxaline-2,3-dione (DNQX) and $1 \mu \mathrm{M}$ strychnine, AMPA and glycine receptor antagonists respectively. Except where noted, recordings also included the NMDA receptor (NMDAR) antagonist D-APV (50 or $100 \mu \mathrm{M})$. Whole-cell recordings were performed from neurons in the lateral VTA with $\mathrm{KCl}$ pipette solution and voltageclamped at $-70 \mathrm{mV}$. Patch pipettes were filled with the following: $125 \mathrm{mM} \mathrm{KCl}, 2.8 \mathrm{mM} \mathrm{NaCl}, 2 \mathrm{mM} \mathrm{MgCl}_{2}, 2 \mathrm{mM}$ ATP-Na ${ }^{+}, 0.3 \mathrm{mM}$ GTP-Na ${ }^{+}, 0.6 \mathrm{mM}$ EGTA, and $10 \mathrm{mM}$ HEPES. In some experiments, EGTA was increased to 15 $\mathrm{mM}$, or GDP- $\beta$-S ( $1 \mathrm{mM})$ was included in the pipette solution as noted. The presence of a large hyperpolarization-activated inward current $\left(I_{h}\right)$ was used to select postsynaptic cells for recording, although we are aware that this metric can allow inclusion of a subset of nondopamine neurons. If the steady-state $\mathrm{I}_{\mathrm{h}}$ was $>25 \mathrm{pA}$ during a step from -50 to $-100 \mathrm{mV}$, the cell was included in analyses. In a subset of recordings, dopamine cells were also identified via fluorescence imaging using a DAT::IRES-cre x TdTomato reporter line. All experiments were performed at $30^{\circ} \mathrm{C}$, maintained by an automatic temperature controller. The series resistance was monitored continuously during the experiment and cells were discarded for deviations $>15 \%$.

\section{Stimulation protocols}

For electrical stimulation, a bipolar stainless-steel stimulating electrode was placed caudal to the VTA 500 $\mu \mathrm{m}$ from the recorded cell; for rostral placement the stimulating electrode was placed within the VTA at 200-500 $\mu \mathrm{m}$ from the recorded cell (Fig. 1A). IPSCs were evoked at 0.1
$\mathrm{Hz}$ using 100- $\mu$ s current pulses. We used input-output curves to identify the stimulation intensity used for plasticity experiments for both rostral and caudal afferents, and the baseline amplitude was at $50 \%$ of this generated curve. No correlation was observed between stimulation intensity and LTP magnitude. This stimulation protocol did not produce action potentials escaping voltageclamp, but in the rare cases that cells began spiking later in the recording, they were excluded from analysis. Channelrhodopsin-induced synaptic currents were evoked at $0.033 \mathrm{~Hz}$ using 0.1 - to 5-ms light pulses from a white LED (Mightex) controlled by driver (ThorLabs) and reflected through a $40 \times$ water immersion lens. When feasible, IPSCs were shown to be $\mathrm{GABA}_{\mathrm{A}}$ receptor mediated by bath application of $10 \mu \mathrm{M}$ bicuculline at the end of recordings. For all stimulus frequencies, intensity remained constant throughout the experiment.

\section{Statistical analysis}

Results are expressed as mean \pm SEM. Significance was determined using a two-tailed paired Student's $t$ test or one-way ANOVA with significance level of $p<0.05$ (Table 1). LTP values are reported as averaged IPSC amplitudes for 10 min just before LTP induction compared with averaged IPSC amplitudes during the 10-min period from 10-20 min after manipulation. Paired-pulse ratios (50-ms interstimulus interval) and coefficient of variation were measured over 10-min epochs of 10-30 IPSCs each. The paired pulse ratio was calculated using the average value for all IPSC2 amplitudes divided by the average value for the corresponding IPSC1 amplitudes and reported as the mean paired pulse ratio for that epoch. $1 / \mathrm{CV}^{2}$ values were determined by dividing the mean amplitude of IPSCs squared recorded over 10-min epochs by the mean variance of these IPSCs.

\section{Materials}

DNQX was obtained from Sigma-Aldrich. D-2-amino-5phosphonopentanoic acid (APV), bicuculline, [D-Ala ${ }^{2}$, $\mathrm{N}$-Me-Phe $\left.{ }^{4}, \mathrm{Gly}^{-} \mathrm{Ol}^{5}\right]$-enkephalin (DAMGO), forskolin, and 
naloxone were obtained from Tocris. Strychnine was obtained from Tocris or Abcam.

\section{Results}

\section{Location of electrical stimulation determines expression of synaptic plasticity}

Most reports examining synaptic plasticity in the VTA have used a stimulating electrode placed within the VTA $200-500 \mu \mathrm{M}$ rostral to the recorded cell in a horizontal slice (Fig. 1A). This approach has been assumed to randomly sample the synaptic inputs onto cells within the VTA. We hypothesized that stimulating caudal to and outside of the VTA, $\sim 500 \mu \mathrm{M}$ from the recorded cell, might bias the inputs differently than with a rostral placement (Fig. 1A). We refer to this as "caudal" stimulation. We recorded IPSCs in putative dopamine cells identified by a large $I_{h}$ and compared synaptic properties using either caudal or rostral electrical stimulation. We did not detect any differences between IPSCs evoked by rostral or caudal stimulation in the onset delay, rise slope, or time of peak amplitude of IPSCs (Fig. 1B-D; paired $t$ test of rostral versus caudal onset delay: $p=0.82^{a}$; rise slope: $p=0.74^{\mathrm{b}}$; time of peak: $p=0.98^{\mathrm{c}}$; rostral: $n=$ 15 cells, caudal: $n=18$ cells). Opioids depress GABAergic inhibition in the VTA; therefore, we compared the opioid-sensitivity of caudal and rostral-stimulated IPSCs. IPSCs from both stimulating locations were depressed by $1 \mu \mathrm{M}$ DAMGO to the same degree (Fig. $1 E, F ;$ rostral $=-55 \pm 8 \%, n=6$ cells; caudal $=-58 \pm$ $9 \%, n=13$ cells; rostral versus caudal: $p=0.86^{\mathrm{d}}$ ). Thus, synaptic properties were similar when stimulating either the rostral or caudal site.

We next used a stimulation protocol known to induce

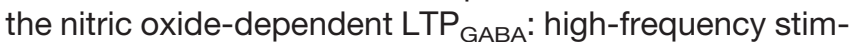
ulation (HFS) consisting of two $100-\mathrm{Hz}$ tetani separated by $10 \mathrm{~s}$ (Nugent et al., 2007). LTP $\mathrm{GABA}_{\mathrm{G}}$ is dependent on NMDAR activation that leads to the release of nitric oxide and activation of a signaling cascade that increases presynaptic GABA release (Nugent et al., 2007, 2009). Instead, HFS of the caudally stimulated site resulted in LTP, even with the NMDAR antagonist, APV $(100 \mu \mathrm{M})$, in the bath solution (Fig. $2 A, B, E ; 157 \pm 23 \%$ of baseline value; paired $t$ test: $p=0.018^{\mathrm{e}}, n=16$ cells). Conversely and consistent with prior results, the same tetanus of a rostrally-placed electrode did not potentiate IPSCs in APV (Nugent et al., 2007; Fig. 2C-E; $90 \pm 11 \%$ of baseline value; paired $t$ test: $p=0.73^{\mathrm{f}}, n=6$ cells). Potentiation after HFS of the caudally-stimulated electrode was correlated with a decrease in paired pulse ratio for cells that potentiated at least $10 \%$ (Fig. $2 F$; baseline: $1.1 \pm 0.2$, after HFS: $0.9 \pm 0.1$ ), without a change in $1 / \mathrm{CV}^{2}$ values (Fig. 2G; baseline: $7.5 \pm 2.1,10-20$ min after HFS: $8.1 \pm 1.4$; paired $t$ test: $p=0.048^{\mathrm{g}}$ and $p=0.70^{\mathrm{h}}$, respectively, $n=$ 12 cells). These findings supported our hypothesis that electrode placement may activate different subsets of afferents and lead to a different outcome when performing protocols to induce synaptic plasticity.
A

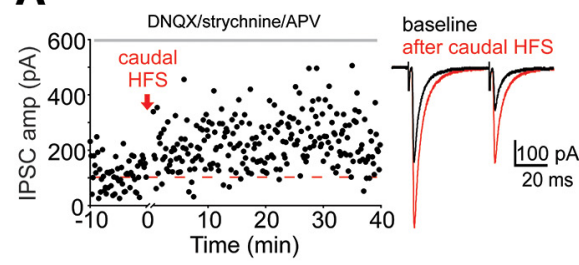

B
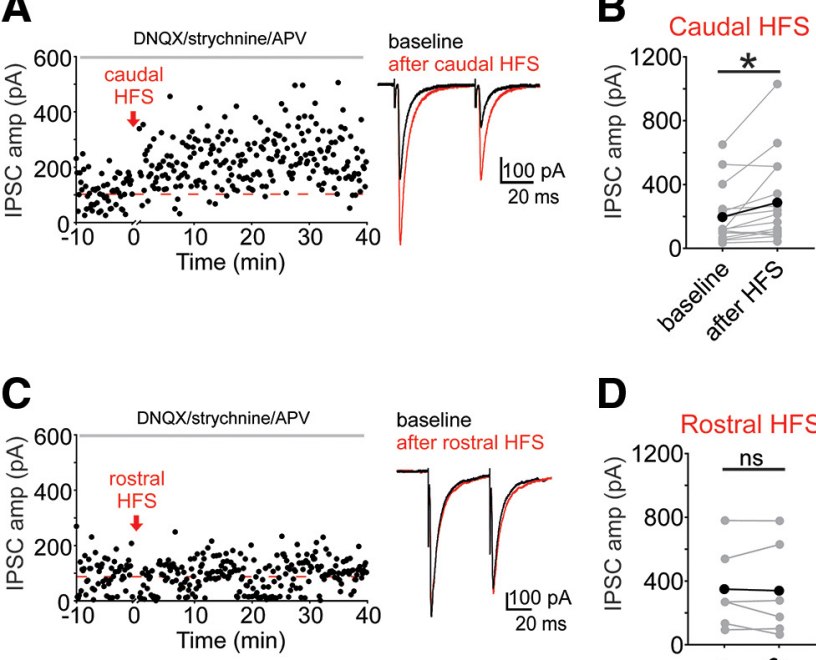

D
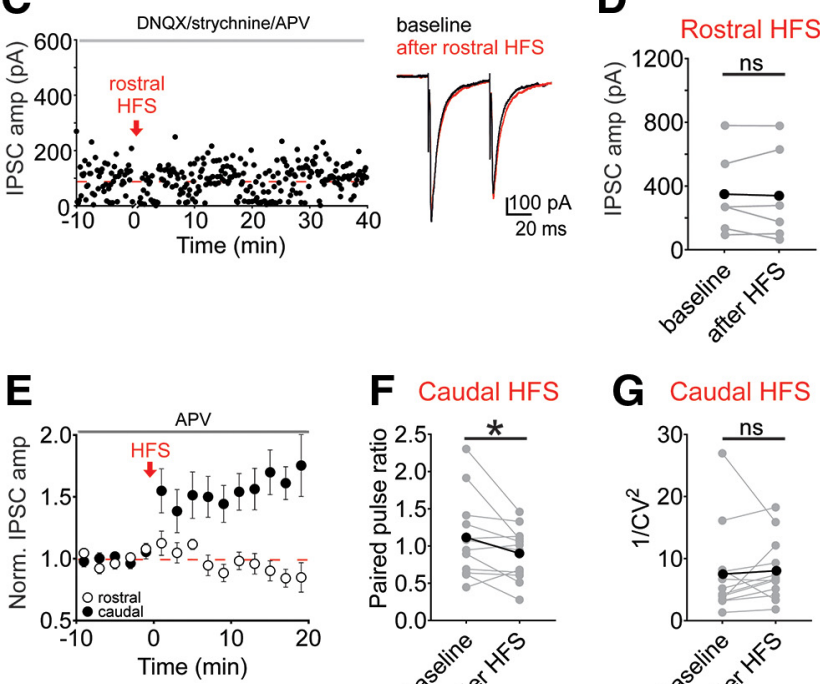

F Caudal HFS

G Caudal HFS
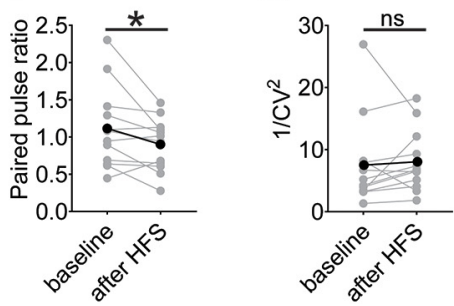

Figure 2. Location of electrical stimulation determines expression of synaptic plasticity. $\boldsymbol{A}$, Representative experiment showing LTP induction by HFS with a caudal electrode placement. Inset, Baseline (black traces) and 10-20 min after HFS (red traces). $\boldsymbol{B}$, Mean IPSC amplitudes from a 10-min baseline and 10-20 min after caudal HFS ( $n=16$ cells). In this and subsequent figures, thicker black symbols/lines represent the mean response across all cells. $\boldsymbol{C}$, Representative experiment with HFS of a rostral electrode. Inset, Baseline (black traces) and 10-20 min after HFS (red traces). $\boldsymbol{D}$, Mean IPSC amplitudes from a 10-min baseline to 10-20 min after rostral HFS ( $n=6$ cells). $\boldsymbol{E}$, Time course of averaged IPSC amplitudes before and after HFS (closed symbols = caudal, $n=16$; open symbols = rostral, $n=$ 6). $\boldsymbol{F}$, Paired pulse ratios before and after caudal HFS from each cell that potentiated $>10 \%$ of basal values ( $n=12$ cells). $\mathbf{G}$, $1 / \mathrm{CV}^{2}$ values before and after caudal HFS from each cell that potentiated $>10 \%$ of basal values ( $n=12$ cells); *p $<0.05$, paired $t$ test of amplitude of 10-min baseline versus 10-20 min after HFS, ns, not significant. Error bars represent SEM.

\section{Low-frequency stimulation (LFS) potentiates caudal- evoked inhibitory inputs}

Inhibitory synapses can be regulated bidirectionally by different afferent stimulation patterns. In an earlier study, LFS of afferents by a stimulating electrode placed rostral to the VTA cell being recorded was used to elicit LTD. LTD is induced by LFS, 6 min of $1-\mathrm{Hz}$ stimulation while voltage clamping the postsynaptic cell at $-40 \mathrm{mV}$ (LFS-LTD; Dacher and Nugent, 2011). LFS-LTD occurs independently of NMDAR activation and is partially blocked by a dopamine D2 receptor antagonist (Dacher and Nugent, 2011). Given the surprising result with HFS of a caudally- 
A

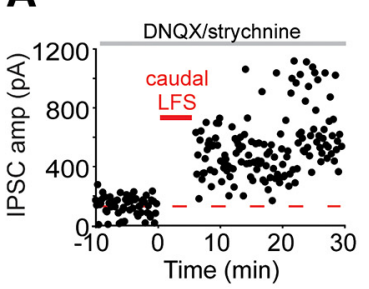

baseline after LFS
B

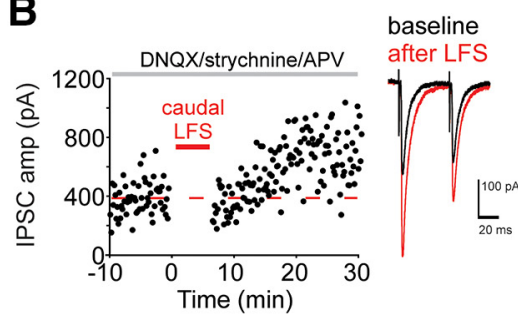

C

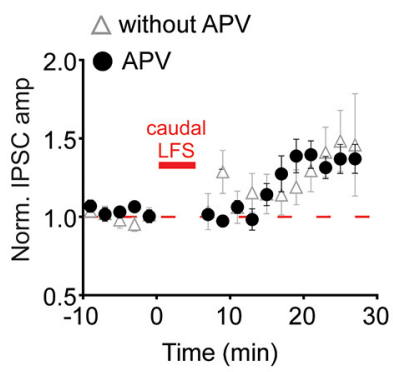

D $\triangle$ without APV

APV

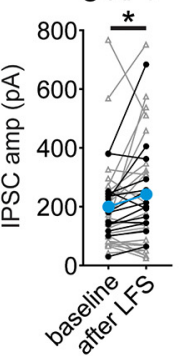

E

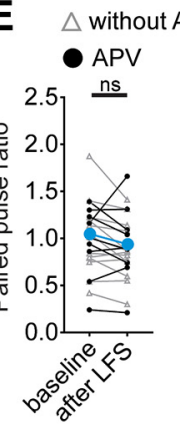

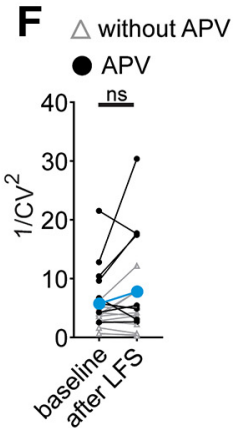

Figure 3. LFS of caudal electrode induces LTP. Representative experiment with LFS with a caudal electrode placement without APV $(\boldsymbol{A})$ or with APV $(\boldsymbol{B})$. Insets, Baseline (black traces) and 10-20 min after LFS (red traces). C, Time course of averaged IPSC amplitudes before and after LFS. $\boldsymbol{D}$, Mean IPSC amplitudes from a 10-min baseline to 10-20 min after caudal LFS ( $n=38$ cells; without APV, $n=25$, with APV, $n=13$ ). $E$, Paired pulse ratios before and after caudal LFS from each cell that potentiated $>10 \%$ of basal values ( $n=22$ cells). $\boldsymbol{F}, 1 / \mathrm{CV}^{2}$ values before and after caudal LFS from each cell that potentiated $>10 \%$ of basal values $(n=19$ cells). $\boldsymbol{D}-\boldsymbol{F}$, Gray symbols/lines, no APV, black symbols/lines, with APV present; $* p<0.05$, paired $t$ test of amplitude of 10 -min baseline versus 10-20 min after LFS, ns, non significant. Error bars represent SEM.

placed electrode, we asked whether LFS of a caudallyplaced stimulating electrode would also induce LTD. Instead, LFS of caudally-evoked IPSCs triggered LTP both in the absence or presence of APV (LFS-LTP GABA; Fig. $3 A-D ; 131 \pm 10 \%$ of baseline value; $p=0.026^{i}, n=$ 38 cells). PPR was not significantly altered in cells potentiating by at least $10 \%$ after LFS (Fig. $3 E$; baseline: $1.0 \pm$ $0.1,10-20$ min after LFS: $0.9 \pm 0.1 ; p=0.058^{\mathrm{j}}, n=22$ cells) and neither were the normalized $1 / \mathrm{CV}^{2}$ values (Fig. $3 F$; baseline: $5.7 \pm 1.1,10-20$ min after LFS: $7.8 \pm 1.8 ; p$ $=0.09^{\mathrm{k}}, n=19$ cells). This surprising finding led us to conclude that as with HFS-induced LTP, previous observations of LTD following LFS were likely dependent on activation of a subset of VTA afferents.

\section{LFS of optically-evoked inhibitory inputs in the VTA does not induce plasticity}

There are many sources of GABAergic inhibition in the VTA and given that LFS can induce either LTD or LTP, depending on stimulation site, we wondered which form of plasticity was predominant when activating GABAergic synapses more globally. We hypothesized that just a subset of VTA synapses express LFS-LTP GABA , so that when using optical stimulation of VGAT ${ }^{+}$inputs in a VGAT-ChR2 transgenic mouse line, both forms of plasticity might occur at different synapses on the same dopamine cell. We used a BAC transgenic mouse line, VGAT-ChR2(H134R)-EYFP, to activate multiple GABAergic inputs in the VTA (Zhao et al., 2011), and used whole-field LED illumination of the slice to activate inhibitory inputs. After generating a stable 10-min baseline of light-evoked IPSCs, we delivered optical LFS while depolarizing the postsynaptic cell to -40
$\mathrm{mV}$. In contrast to what we observed with caudal electrical stimulation, the mean light-evoked IPSC amplitude was unchanged after optical LFS (Fig. 4A-C; $102 \pm 10 \%$ of baseline value; $p=0.83^{\prime}, n=7$ cells). PPR was not significantly altered after LFS (data not shown; baseline: $0.72 \pm 0.07,10-20 \mathrm{~min}$ after LFS: $0.72 \pm 0.05, p=0.97^{\mathrm{m}}$, $n=7$ cells) and neither were $1 / \mathrm{CV}^{2}$ values (data not shown; baseline: $20.0 \pm 2.4,10-20$ min after LFS: $20.2 \pm$ 3.6, $p=0.95^{\mathrm{n}}, n=7$ cells).

\section{Forskolin potentiation does not occlude LFS-induced LTP}

Forskolin is known to potentiate many synapses. Forskolin activates adenylyl cyclase which potentiates GABAergic synapses in the VTA (Melis et al., 2002; Nugent et al., 2009) as well as at many excitatory and inhibitory synapses throughout the CNS (Briggs et al., 1988; Greengard et al., 1991; Cameron and Williams, 1993; Chavez-Noriega and Stevens, 1994; Huang and Kandel, 1994, 1998; Weisskopf et al., 1994; Bonci and Williams, 1996; Salin et al., 1996; Bonci and Williams, 1997; Castro-Alamancos and Calcagnotto, 1999; Linden and Ahn, 1999; Mellor et al., 2002). Both prior VTA studies using forskolin and stimulating GABAergic VTA afferents used rostral electrical stimulation. We wondered whether forskolin would also potentiate inputs evoked with caudal afferent stimulation or whether these synapses would prove distinct again. We found that $10 \mu \mathrm{M}$ forskolin potentiated IPSCs stimulated with a caudally-placed electrode (Fig. $5 A-C ; 183 \pm 19 \%$ of baseline value; $p=$ $0.003^{\circ}, n=14$ cells), although PPR was not significantly altered after forskolin (data not shown; baseline: $0.9 \pm$ 
A optical full field light
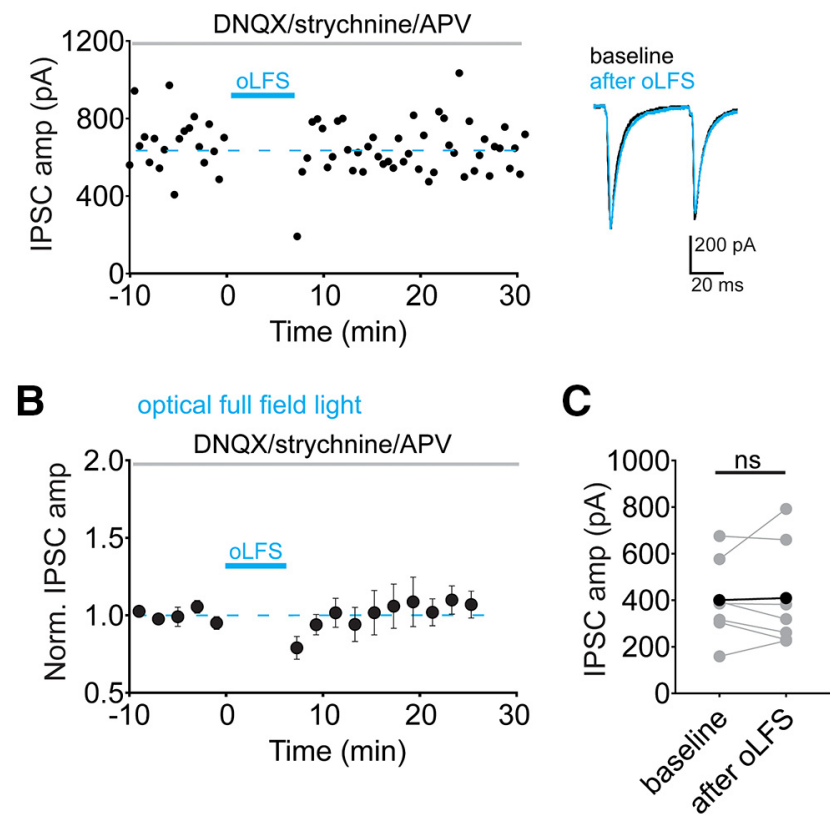

Figure 4. No effect with low-frequency optical stimulation of VGAT ${ }^{+}$synapses. $\boldsymbol{A}$, Representative experiment with optical LFS. Inset, Baseline (black traces) and 10-20 min after LFS (red traces). $\boldsymbol{B}$, Time course of averaged IPSC amplitudes before and after LFS ( $n=$ 7). C, Mean IPSC amplitudes from a 10-min baseline to 10-20 min after optical LFS ( $n=7$ cells). Error bars represent SEM, ns, not significant.

$0.1,10-20$ min after LFS: $0.9 \pm 0.1 ; p=0.65^{p}, n=13$ cells). Forskolin potentiation occludes NMDAR-dependent LTP $_{\text {GABA }}$ (Nugent et al., 2009). Therefore, we performed occlusion experiments to ask if forskolin potentiation occludes caudal LFS-induced LTP. However, forskolin-induced potentiation did not occlude further potentiation by LFS (Fig. $5 D-F ; 131 \pm 10 \%$ of baseline value; $p=0.046^{q}, n=10$ cells). These data suggest that the mechanism underlying
A

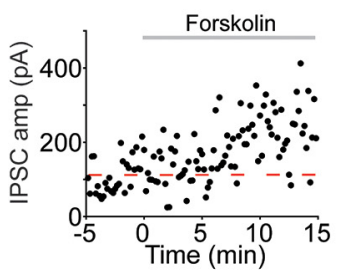

D

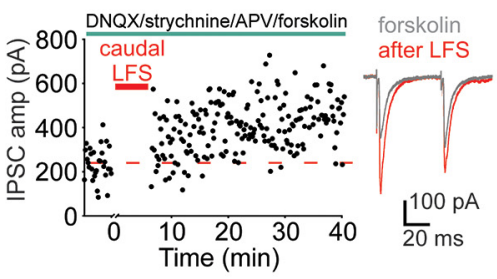

B

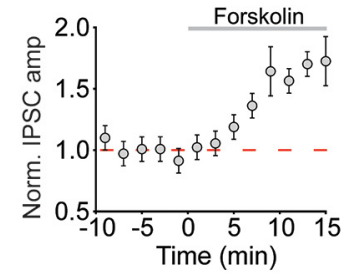

E

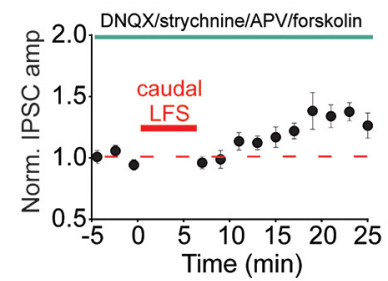

\section{C}

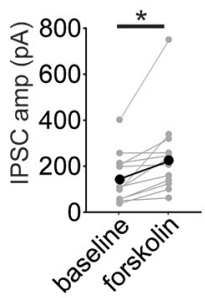

$\mathbf{F}$

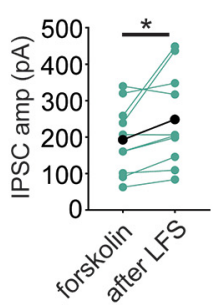

Figure 5. Forskolin potentiates GABAergic synapses evoked with caudal stimulation but does not prevent subsequent potentiation by caudal LFS. $\boldsymbol{A}$, Representative experiment with $10 \mu \mathrm{M}$ forskolin. Inset, Baseline (black traces) and in forskolin (gray traces). $\boldsymbol{B}$, Time course of averaged IPSC amplitudes before and during forskolin. $\boldsymbol{C}$, Mean IPSC amplitudes from a 10-min baseline to 10-20 min after forskolin addition ( $n=14$ cells). $\boldsymbol{D}$, Representative experiment with caudal LFS after potentiation by $10 \mu \mathrm{M}$ forskolin. Inset: baseline in forskolin (gray traces) and 10-20 min after LFS (red traces). $\boldsymbol{E}$, Time course of averaged IPSC amplitudes before and after caudal LFS after forskolin-induced potentiation was established. $\boldsymbol{F}$, Mean IPSC amplitudes from a 10-min baseline to 10-20 min after forskolin ( $n=10$ cells); $* p<0.05$, paired $t$ test of amplitude of 10-min baseline versus 10-20 min after forskolin or LFS. Error bars represent SEM. 
A
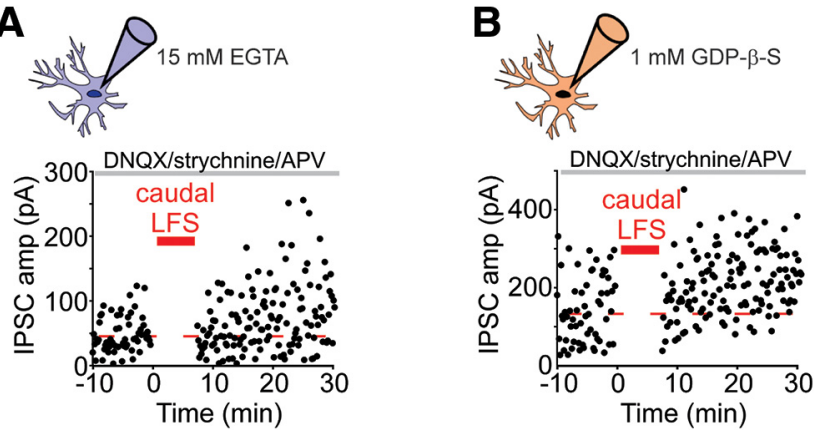

C

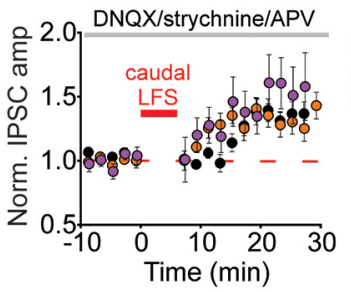

D

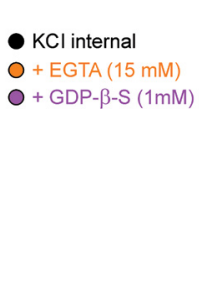

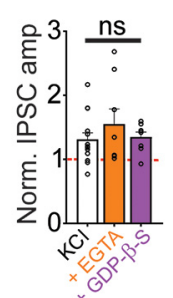

Figure 6. LFS-induced LTP does not require postsynaptic calcium elevation or GPCR activation. $\boldsymbol{A}$, Representative experiment with caudal LFS when 15 mM EGTA was included in the patch pipette. Inset, Baseline (black traces) and 10-20 min after LFS (red traces). B, Representative experiment with caudal LFS when $1 \mathrm{mM}$ GDP- $\beta$-S was included in the patch pipette intracellular solution. Inset, Baseline (black traces) and 10-20 min after LFS (red traces). C, Time course of averaged IPSC amplitudes before and after caudal LFS with: normal $\mathrm{KCl}$ internal solution (black symbols, $n=14$ ), or with $15 \mathrm{mM}$ EGTA (orange symbols, $n=8$ ) or $1 \mathrm{mM}$ GDP-b-S (purple symbols, $n=8$ ) in the pipette solution. $\boldsymbol{D}$, Mean IPSC amplitudes normalized to a 10 minute baseline period at 10-20 min after LFS with the different internal solutions listed in $\boldsymbol{C}$. Error bars represent SEM, ns, not significant.

LFS-induced LTP is distinct from that of forskolin potentiation.

\section{LFS-induced LTP does not require postsynaptic G-protein-coupled receptor (GPCR) signaling and is not prevented by postsynaptic EGTA}

Potentiation after LFS was not associated with a significant change in the paired pulse ratio or coefficient of variation (Fig. $3 E, F$ ), suggesting that the mechanism may reflect an increased GABAergic sensitivity of the postsynaptic cells. Most forms of LTP are triggered by increases in calcium concentration in the postsynaptic cell, and so we tested whether LFS-LTP requires a rise in postsynaptic calcium. When the concentration of the calcium chelator, EGTA, was raised to $15 \mathrm{mM}$ in the patch pipette, LFS still resulted in potentiation of caudally-evoked IPSCs (Fig. $6 A, C, D ; 155 \pm 24 \%$ of baseline value; $n=8$ cells). An alternative postsynaptic mechanism might require activation of receptors on the postsynaptic cell other than $G_{A B A}$ receptors. For example, the report of LFS-LTD found that depression was partially dependent on dopamine D2 receptors (Dacher and Nugent, 2011), which are coupled to the $G_{i}$ subtype of GPCRs. When we included an inhibitor of GPCR activity ( $1 \mathrm{mM}$ GDP- $\beta \mathrm{S})$ in the patch

pipette to block all postsynaptic GPCR signaling, LFS still potentiated caudally-evoked IPSCs (Fig. 6B,C,D; $135 \pm$ $8 \%$ of baseline value; $n=8$ cells). The magnitude of LTP after LFS was not significantly different for high EGTA or GDP- $\beta$-S conditions than experiments with normal $\mathrm{KCl}$ internal solution $\left(F_{(2,27)}=0.77, p=0.48^{r}, n=8\right.$ cells high EGTA, $n=8$ cells GDP- $\beta$-S, $n=14$ cells normal KCl). Together our results suggest a mechanism that does not require postsynaptic GPCRs or $\mathrm{Ca}^{2+}$ influx. Future experiments will be needed to understand this novel form of LTP.

\section{Discussion}

Most reports describing synaptic plasticity in the VTA used electrical stimulation, which can miss the possibility of circuit specificity that can now be probed using optogenetic tools. For example, LTP GABA $_{\text {(Nugent et al., 2007) }}$ was found to vary depending on presynaptic source (Simmons et al., 2017; Polter et al., 2018). Here, we report that inhibitory synapses in the VTA have different requirements for inducing LTP depending on the placement of the stimulating electrode.

\section{Synaptic plasticity induction}

Using the same stimulation protocol but with the electrode at a site that deviated from the usual placement, we serendipitously discovered that we could induce NMDARindependent LTP using either HFS or LFS. Pairing postsynaptic cell depolarization with afferent stimulation, to substitute for a strong tetanus, is a classic approach used to induce LTP in the hippocampus (Nicoll, 2017). However, this method for inducing LTP is generally due to NMDAR activation. Instead, robust caudal LFS-induced LTP in the VTA was elicited in the presence of an NMDAR antagonist. Previously described LFS-LTD in the VTA is also NMDAR independent (Dacher and Nugent, 2011). How might the same pattern of afferent stimulation result in opposite synaptic plasticity outcomes? One likely explanation is that different electrode locations preferentially activate different subsets of afferents in the VTA slice. The VTA dopamine cells are innervated both by local GABA neurons and by GABA projections originating in regions throughout the brain that may differ in protein expression leading to different forms of synaptic plasticity. Another possibility is that the timing of inputs differs when using the two stimulating electrode locations; however, we did not observe a significant difference in onset delay, rise slope, or time of peak amplitude of IPSCs from caudal versus rostral. We speculate that LFS with mild depolarization may lead to release of a signaling molecule from the postsynaptic or presynaptic cell. If different synapses express different receptor subtypes for that signaling molecule, then release via LFS could result in distinct synaptic strength changes. Future experiments will be needed to determine whether HFS-LTP and LFS-LTP result, e.g., from activation by metabotropic glutamate, endocannabinoid, or dopamine receptors.

\section{LFS and synaptic plasticity}

Numerous studies have shown that LFS induces LTD, often when paired with modest postsynaptic depolariza- 
tion (Bear and Malenka, 1994; Gutlerner et al., 2002). There are fewer instances where LFS induces LTP, and these generally required pairing with strong depolarization to activate NMDARs (Bonci and Malenka, 1999; Lanté et al., 2006; Ikeda et al., 2007; Dringenberg et al., 2014). Here, we found that LFS potentiates VTA GABA synapses with mild depolarization and LFS that did not require NMDAR activation, an apparently rare mechanism at CNS synapses. One other example is at the excitatory synapse from lateral perforant path to dentate gyrus cells, where LFS also potentiates synapses independently of NMDAR activation (Gonzalez et al., 2014). However, to our knowledge, ours is the first report of LTP elicited by LFS at GABAergic synapses.

\section{GABAergic afferents innervating the VTA}

Exposure to drugs of abuse causes LTP at excitatory synapses on VTA DA cells (Ungless et al., 2001; Saal et al., 2003). Many drugs of abuse also block LTP GABA $_{\text {in }}$ the VTA (Nugent et al., 2007; Guan and Ye, 2010; Niehaus et al., 2010; Graziane et al., 2013). The net result of these drug-induced changes in synaptic strength is thought to be increased dopamine cell firing via enhanced excitatory drive and disinhibition. However, if more types of synaptic plasticity exist than previously suspected, differential effects of drugs of abuse on VTA afferents may produce a more nuanced effect on dopamine cell firing. LTP $\mathrm{GABA}_{\mathrm{GA}}$ is expressed at VTA $\mathrm{GABA}_{\mathrm{GA}} \rightarrow \mathrm{VTA}$ but not at $\mathrm{RMTg}_{\mathrm{GABA}} \rightarrow \mathrm{VTA}$ synapses; by analogy, it is likely that the HFS-induced and LFS-induced LTP we report here are expressed only at a subset of inputs. It is difficult to be certain precisely which afferents are sufficiently close to the caudal stimulation site to be activated by our stimulus protocol. Regions other than the RMTg that are located caudal to the VTA with reported GABAergic innervation include: the dorsal raphe, periaqueductal gray, pedunculopontine nucleus, and laterodorsal tegmentum (Beier et al., 2015; Omelchenko and Sesack, 2010; Faget et al., 2016; Ntamati et al., 2018). Given the placement of the caudal electrode in our experiments, it is possible that the presynaptic source of those inputs is from one of these caudal brain regions, although it is alternatively possible that regions located elsewhere in the brain send projections that pass through the caudal stimulation location.

In conclusion, depending on stimulation site, HFS and LFS can induce LTP at GABAergic synapses in the VTA via a mechanism that does not require NMDAR activation. These results support the recent findings that some forms

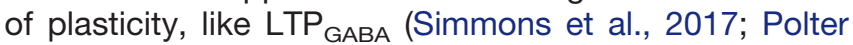
et al., 2018), are selectively expressed at some synapses but not others. Together, this points toward a specificity of synaptic plasticity based on presynaptic partner and postsynaptic cell identity. Furthermore, this study highlights the fact that there may be plasticity mechanisms in the VTA still to be identified.

\section{References}

Bear MF, Malenka RC (1994) Synaptic plasticity: LTP and LTD. Curr Opin Neurobiol 4:389-399.

Beier KT, Steinberg EE, Deloach KE, Xie S, Miyamichi K, Schwarz L, Gao XJ, Kremer EJ, Malenka RC, Luo L (2015) Circuit architecture of VTA dopamine neurons revealed by systematic input-output mapping. Cell 162:622-634.

Bonci A, Williams JT (1996) A common mechanism mediates longterm changes in synaptic transmission after chronic cocaine and morphine. Neuron 16:631-639.

Bonci A, Williams JT (1997) Increased probability of GABA release during withdrawal from morphine. J Neurosci 17:796-803.

Bonci A, Malenka RC (1999) Properties and plasticity of excitatory synapses on dopaminergic and GABAergic cells in the ventral tegmental area. J Neurosci 19:3723-3730.

Briggs CA, McAfee DA, McCaman RE (1988) Long-term regulation of synaptic acetylcholine release and nicotinic transmission: the role of cyclic AMP. Br J Pharmacol 93:399-411.

Cameron DL, Williams JT (1993) Dopamine D1 receptors facilitate transmitter release. Nature 366:344-347.

Castro-Alamancos MA, Calcagnotto ME (1999) Presynaptic longterm potentiation in corticothalamic synapses. J Neurosci 19: 9090-9097.

Chavez-Noriega LE, Stevens CF (1994) Increased transmitter release at excitatory synapses produced by direct activation of adenylate cyclase in rat hippocampal slices. J Neurosci 14:310-317.

Dacher M, Nugent FS (2011) Morphine-induced modulation of LTD at GABAergic synapses in the ventral tegmental area. Neuropharmacology 61:1166-1171.

Dringenberg HC, Branfield Day LR, Choi DH (2014) Chronic fluoxetine treatment suppresses plasticity (long-term potentiation) in the mature rodent primary auditory cortex in vivo. Neural Plast 2014:571285

Faget L, Osakada F, Duan J, Ressler R, Johnson AB, Proudfoot JA, Yoo JH, Callaway EM, Hnasko TS (2016) Afferent inputs to neurotransmitter-defined cell types in the ventral tegmental area. Cell Rep 15:2796-2808.

Gonzalez J, Morales IS, Villarreal DM, Derrick BE (2014) Lowfrequency stimulation induces long-term depression and slow onset long-term potentiation at perforant path-dentate gyrus synapses in vivo. J Neurophysiol 111:1259-1273.

Graziane NM, Polter AM, Briand LA, Pierce RC, Kauer JA (2013) Kappa opioid receptors regulate stress-induced cocaine seeking and synaptic plasticity. Neuron 77:942-954.

Greengard P, Jen J, Nairn AC, Stevens CF (1991) Enhancement of the glutamate response by CAMP-dependent protein kinase in hippocampal neurons. Science 253:1135-1138.

Guan YZ, Ye JH (2010) Ethanol blocks long-term potentiation of GABAergic synapses in the ventral tegmental area involving muopioid receptors. Neuropsychopharmacology 35:1841-1849.

Gutlerner JL, Penick EC, Snyder EM, Kauer JA (2002) Novel protein kinase A-dependent long-term depression of excitatory synapses. Neuron 36:921-931.

Huang YY, Kandel ER (1994) Recruitment of long-lasting and protein kinase A-dependent long-term potentiation in the CA1 region of hippocampus requires repeated tetanization. Learn Mem 1:74-82.

Huang YY, Kandel ER (1998) Postsynaptic induction and PKAdependent expression of LTP in the lateral amygdala. Neuron 21:169-178.

Ikeda R, Takahashi Y, Inoue K, Kato F (2007) NMDA receptorindependent synaptic plasticity in the central amygdala in the rat model of neuropathic pain. Pain 127:161-172.

Kodangattil JN, Dacher M, Authement ME, Nugent FS (2013) Spike timing-dependent plasticity at GABAergic synapses in the ventral tegmental area. J Physiol 591:4699-4710.

Lanté F, Cavalier M, Cohen-Solal C, Guiramand J, Vignes M (2006) Developmental switch from LTD to LTP in low frequency-induced plasticity. Hippocampus 16:981-989.

Linden DJ, Ahn S (1999) Activation of presynaptic cAMP-dependent protein kinase is required for induction of cerebellar long-term potentiation. J Neurosci 19:10221-10227.

Liu QS, Pu L, Poo MM (2005) Repeated cocaine exposure in vivo facilitates LTP induction in midbrain dopamine neurons. Nature 437:1027-1031. 
Melis M, Camarini R, Ungless MA, Bonci A (2002) Long-lasting potentiation of GABAergic synapses in dopamine neurons after a single in vivo ethanol exposure. J Neurosci 22:2074-2082.

Mellor J, Nicoll RA, Schmitz D (2002) Mediation of hippocampal mossy fiber long-term potentiation by presynaptic Ih channels. Science 295:143-147.

Nicoll RA (2017) A brief history of long-term potentiation. Neuron 93:281-290.

Niehaus JL, Murali M, Kauer JA (2010) Drugs of abuse and stress impair LTP at inhibitory synapses in the ventral tegmental area. Eur J Neurosci 32:108-117.

Ntamati NR, Creed M, Achargui R, Lüscher C (2018) Periaqueductal efferents to dopamine and GABA neurons of the VTA. PLoS One 13:e0190297.

Nugent FS, Penick EC, Kauer JA (2007) Opioids block long-term potentiation of inhibitory synapses. Nature 446:1086-1090.

Nugent FS, Niehaus JL, Kauer JA (2009) PKG and PKA signaling in LTP at GABAergic synapses. Neuropsychopharmacology 34: 1829-1842.

Omelchenko N, Sesack SR (2010) Periaqueductal gray afferents synapse onto dopamine and GABA neurons in the rat ventral tegmental area. J Neurosci Res 88:981-991.

Padgett CL, Lalive AL, Tan KR, Terunuma M, Munoz MB, Pangalos MN, Martínez-Hernández J, Watanabe M, Moss SJ, Luján R, Lüscher C, Slesinger PA (2012) Methamphetamine-evoked depression of GABAB receptor signaling in GABA neurons of the VTA. Neuron 73:978-989.

Polter AM, Bishop RA, Briand LA, Graziane NM, Pierce RC, Kauer JA (2014) Poststress block of kappa opioid receptors rescues longterm potentiation of inhibitory synapses and prevents reinstatement of cocaine seeking. Biol Psychiatry 76:785-793.
Polter AM, Barcomb K, Tsuda AC, Kauer JA (2018) Synaptic function and plasticity in identified inhibitory inputs onto VTA dopamine neurons. Eur J Neurosci 47:1208-1218.

Saal D, Dong Y, Bonci A, Malenka RC (2003) Drugs of abuse and stress trigger a common synaptic adaptation in dopamine neurons. Neuron 37:577-582.

Salin PA, Malenka RC, Nicoll RA (1996) Cyclic AMP mediates a presynaptic form of LTP at cerebellar parallel fiber synapses. Neuron 16:797-803.

Simmons DV, Petko AK, Paladini CA (2017) Differential expression of long-term potentiation among identified inhibitory inputs to dopamine neurons. J Neurophysiol 118:1998-2008.

Ting JT, Daigle TL, Chen Q, Feng G (2014) Acute brain slice methods for adult and aging animals: application of targeted patch clamp analysis and optogenetics. Methods Mol Biol 1183:221-242.

Ungless MA, Whistler JL, Malenka RC, Bonci A (2001) Single cocaine exposure in vivo induces long-term potentiation in dopamine neurons. Nature 411:583-587.

Watabe-Uchida M, Zhu L, Ogawa SK, Vamanrao A, Uchida N (2012) Whole-brain mapping of direct inputs to midbrain dopamine neurons. Neuron 74:858-873.

Weisskopf MG, Castillo PE, Zalutsky RA, Nicoll RA (1994) Mediation of hippocampal mossy fiber long-term potentiation by cyclic AMP. Science 265:1878-1882.

Zhao S, Ting JT, Atallah HE, Qiu L, Tan J, Gloss B, Augustine GJ, Deisseroth K, Luo M, Graybiel AM, Feng G (2011) Cell type-specific channelrhodopsin-2 transgenic mice for optogenetic dissection of neural circuitry function. Nat Methods 8:745752.

Zhuang X, Masson J, Gingrich JA, Rayport S, Hen R (2005) Targeted gene expression in dopamine and serotonin neurons of the mouse brain. J Neurosci Methods 143:27-32. 